\title{
The Relationship between 50 meters Freestyle Technique Swimming Performance and Anthropometric and Motoric Features in 9-13 Age Group Swimmers
}

\author{
9-13 Yaş Grubu Yüzücülerde 50 m Serbest Teknik \\ Yüzme Performansı ile Antropometrik ve Motorik \\ Özellikler Arasındaki ilişki
}

\author{
Selbi Pehlivan (iD) https://orcid.org/0000-0003-4437-1949 \\ Institute of Medical Sciences, Düzce University, Duzce, Turkey
}

Zeynep İnci Karadenizli $\mathbf{i}^{\mathbf{1}}$ iD https://orcid.org/0000-0002-9159-999X
Faculty of Sports Sciences, Düzce University, Duzce, Turkey

Received: September 2, 2019 Accepted: September 18, 2019 Online Published: September 30, 2019

DOl: 10.30655/besad.2019.21 https//:doi.org/10.30655/besad.2019.21

\begin{abstract}
The aim of this study is to examine the relationship between 50 meter freestyle technique swimming performance and anthropometric and motoric features 9 -13 age group swimmers. 8 boys lage: $X=12,00 \pm 1,06$ yrs, body weight: $X=$ $48,90 \pm 8,37 \mathrm{~kg}$, body height: $X=155,50 \pm 8,58 \mathrm{~cm}$ ) and 7 girls (age: $X=11,00 \pm 1,29 \mathrm{yrs}$, body weight: $X=42,77 \pm 11,57 \mathrm{~kg}$, body height: $X=148,57 \pm 9,79 \mathrm{~cm}$ ), in total 15 children swimmers participated in the study, from Düzce Youth Services Sports Club. The swimmers involved in the study consisted of players who had swimming training for one year and exercised regularly for two hours twice a week. Some anthropometric (body weight, body-mass index, body height, hand and arm span), motoric (speed, endurance, flexibility, agility, hand grip) and swimming performance measurements (50 mt freestyle technique) are carried out. For the data analysis, on the SPSS 22 packaged software descriptive statistics and Pearson Correlation analysis are carried out. Significance level is accepted as ( $p<0.05)$. As a result, of anthropometric properties, negative correlation between height and arm span and swimming performance of 50 meters, positive correlation between arm span detected. Of motoric properties, positive correlation is detected between speed (30 mt sprint) and swimming performance, also the stroke frequency in 50 meters. Negative correlation is detected between endurance and hand grip (left) and swimming performance of 50
\end{abstract}

${ }^{1}$ Corresponding author: Zeynep İnci Karadenizli

Düzce Üniversitesi Spor Bilimleri Fakültesi Konuralp Yerleşkesi, Merkez, Düzce

incikaradenizli@ duzce.edu.tr 
meters. In addition to these, positive correlation is detected between the stroke frequency and swimming performance of 50 meters. It is advised to swimming coaches and physical education teachers that when the selection of talents for short distance swimmers, they should prefer players who have longer body height and arm span. In addition, it is recommended to do training plan that improves to speed, endurance, hand grip and the stroke frequency.

Keywords: Anthropometry, motoric features, performance, swimming

\section{Öz}

Araştırmanın amacı, 9-13 yaş grubu yüzücülerde, 50 metre serbest yüzme performansı ile antropometrik ve motorik özellikler arasındaki ilişkiyi incelemektir. Araştırmaya Düzce Gençlik Hizmetleri Spor Kulübü sporcularından, 8 erkek (yaş: $X=12,00 \pm 1,06$ yıl, vücut ağırlığı: $X=48,90 \pm 8,37 \mathrm{~kg}$, boy: $X=155,50 \pm 8,58 \mathrm{~cm}$ ) ve 7 kız (yaş: $X=11,00 \pm 1,29$ yıl, vücut ağırlığı: $X=42,77 \pm 11,57 \mathrm{~kg}$, boy: $X=148,57 \pm 9,79 \mathrm{~cm}$ ) toplamda 15 çocuk yüzücü katılmıştır. Araştırmada yer alan yüzücüler, bir yıl yüzme eğitimi alan ve haftada iki gün 2 saat düzenli antrenman yapan sporculardan oluşturulmuştur. Katılımcılara bazı antropometrik (vücut ağırlığı, beden kütle indeksi, boy, el ve kulaç uzunluğu), motorik (sürat, dayanıklıık, esneklik, çeviklik, kavrama kuvveti) ve yüzme performans ölçümleri (50 metre serbest teknik) yapılmıştır. Verilerin analizleri, Pearson Korelasyon analizi ile değerlendirilmiştir. Analizlerde (p<0.05) güvenilirlik düzeyi kullanılmıştır. Sonuç olarak antropometrik özelliklerden; boy ve kulaç uzunluğu ile 50 metre yüzme performansı arasında negatif ilişki tespit edilmiştir. Motorik özelliklerden; sürat (30 m sprint) ile $50 \mathrm{metre}$ yüzme performansı ve kulaç sayısı arasında pozitif ilişki bulunmuştur. Dayanıklılı ve kavrama kuvveti (sol) ile 50 metre yüzme performansı arasında negatif ilişki bulunmuştur. Bunların yanı sıra kulaç sayısı ile $50 \mathrm{~m}$ yüzme performansı arasında pozitif ilişki olduğu görülmüştür. Yüzme antrenörlerine ve beden eğitimi öğretmenlerine, kısa mesafe yüzücüler için yetenek seçiminde boy ve kulaç uzunluğu büyük olan çocukları tercih etmeleri önerilmektedir. Ayrıca, sürat, dayanıklıık, kavrama kuvveti ve kulaç sayısını geliştirecek planlamalar yaparak antrenman yaptırmaları tavsiye edilmektedir.

Anahtar kelimeler: Antropometri, motorik özellikler, performans, yüzme

\section{Giriş}

Yüzme, hem yarışma sporu hem de rekreatif etkinlik olarak her yaş kategorisi için fiziksel ve ruhsal dinlendirici bir etkinliktir. Bu nedenle fazlaca tercih edilen bir spor dalı olduğu bilinmektedir (Güler, 2000). Bu spor dalında yüzücülerin üst düzey performans göstermeleri ve aynı zamanda kalori harcamaları için belli bir yoğunlukta teknik beceri ile yüzmeleri gerekmektedir. Sporcunun yüksek performansa ulaşabilmesi için biyomekanik, fizyolojik, motorik ve antropometrik özelliklerinin iyi geliştirmiş olması gerekmektedir. Ayrıca sporcunun psikolojik durumu, beslenme şekli de performansı etkileyen diğer öğelerdendir (Bozdoğan, 2003).

Yüzücüler, belirli bir mesafeyi mümkün olan en kısa sürede kat etmeyi amaçlamaktadır. Bu mesafe kat edilirken kulaç sayısı, kulaç uzunluğu, ayak vuruşu ve boy uzunluğu önem taşımaktadır. Günümüzdeki önemli yarışlardan sonra çıkarılan raporlar, yüzme hızı ve ara derecelerin yanı sıra kulaç temposu ve kulaç mesafelerinin hesaplanmalarını da içermektedir. Yüzücüler, daha az kol çekişi yaparak yüzülen süreyi azaltmayı ve bu sayede daha ekonomik bir çalışmayı hedeflemektedir (Çelebi, 2008; Maglischo, 2003; Özüak, 2009). Diğer yandan, maksimal yüzme hızı, kulaç sayısı ile ilişkilendirilmiş olmasına rağmen, kulaç uzunluğunun daha önemli olduğuna da işaret edilmektedir (Wakayoshi vd., 1995).

Elit yüzücülerin, kinematik verileri ve enerji metabolizması değerlerinin yüksek seviyede olduğu, ayrıca bunlarla birlikte antropometrik özelliklerin de bu yüzücülerin performansları üzerinde anlamlı etkileri olduğu belirtilmektedir (Jurimae vd., 2007). Genç yüzücülerde de boy ve kulaç uzunluğu gibi antropometrik özelliklerin (Jurimae vd., 2007) ve yüzerken kaplanan alanın (Helmuth, 1980) en iyi performans ile ilişkili olduğu ifade edilmektedir. Yüzme hızındaki gelişmenin, kulaç uzunluğundaki artışa bağlı olduğu da yapılan bir araştırma sonucunda rapor edilmiştir (Tella vd., 2002). Genç 
yüzücülerin performansı, antropometrik özellikler ile yüksek ilişkilidir, en önemli performans belirleyicilerden biri kulaç uzunluğudur (Latt vd., 2010). Bunlara ek olarak, genç yüzücülerde, kulaç oranı ve kritik hızın, yüzme performansını belirlemede en iyi ipuçlarından olduğu da başka bir çalışma ile belirtilmektedir (Vitor \& Böhme, 2010).

Hızlı yüzücülerin, çift kol açıklığı, yüzey alanları, kulaç uzunluğu, yüzme hızı, kritik hızları büyük olan ve uzun boylu sporcular oldukları, ayrıca bu özelliklerin, genç yüzücülerin performansları ile ilişkili olduğu araştırmalar ile tespit edilmiştir (Jurimae vd., 2007; Vitor \& Böhme, 2010). Yaş aralığı 11-12 yıl olan kız ve erkek yüzücüler ile yapılan çalışmada da en iyi performans gösterenlerin, uzun boylu, büyük yüzey alanına ve en iyi kulaç mekaniğine sahip olanlar olduğu ifade edilmektedir (Morais vd., 2013). Diğer taraftan ise başka çalışmalarda, kulaç sayısı ve kulaç uzunluğunun, yarışma süresiyle istatistiki olarak anlamlı ilişkili olmadığı belirtilmektedir (Smith vd. 2002; Toussaint \& Beek, 1992; Wakayoshi vd., 1993; Wakayoshi vd., 1995).

Literatürdeki bu farklı görüşlerden yola çıkarak çalışmamızda, yüzme performansını incelemeyi amaçladık. Bahsedilen faktörlere ek olarak diğer antropometrik ve motorik özelliklerin de yüzme derecelerini etkileyebileceğini düşünmekteyiz. Bu nedenle, 9-13 yaş grubu çocukların bazı antropometrik ve motorik özellik değerlerini inceleyerek bu değişkenlerin, 50 metre serbest teknik yüzme performansına etkisinin olup olmadığını incelemek istedik. Araştırma sonuçlarının, yüzme sporuna ve spor bilimlerine katkı sağlayabileceğini düşünmekteyiz.

\section{Yöntem}

9-13 yaş grubu yüzücülerde, 50 mt serbest yüzme performansı ile antropometrik ve motorik özellikler arasındaki ilişkinin incelendiği çalışmada, bağımsız değiş̧kenler; boy, kulaç, el uzunluğu, vücut ağırlığı, sürat, esneklik, kavrama kuvveti, dayanıklılık ve çeviklik özelliği, bağımlı değişken ise; 50 mt serbest teknik yüzme derecesidir.

\section{Katılımcılar}

Araştırmaya Düzce Gençlik Hizmetleri Spor Kulübü sporcularından, 8 erkek (yaş: $X=12,00 \pm 1,06$ yıl, vücut ağırlığı: $X=48,90 \pm 8,37 \mathrm{~kg}$, boy: $X=155,50 \pm 8,58 \mathrm{~cm}$ ) ve $7 \mathrm{kız}$ (yaş: $X=11,00 \pm 1,29$ yıl, vücut ağırlığı: $X=42,77 \pm 11,57 \mathrm{~kg}$, boy: $X=148,57 \pm 9,79 \mathrm{~cm}$ ) toplamda 15 çocuk yüzücü katılmıştır.

Bu araştırmanın evreni; Düzce ilinde yüzme sporuyla ilgilenen 9-13 yaş grubu yaklaşık 50 sporcudan oluşmaktadır. Araştırmanın örneklemini ise; bu evrenden seçilen ve araştırma grubunu temsil eden 8 erkek, 7 kız olmak üzere toplam 15 yüzücü oluşturmaktadır. Araştırma grubunu oluşturan katılımcılar, Düzce Gençlik Hizmetleri Spor Kulübü sporcuları arasından gönüllülük esasına dayanarak oluşturulmuştur. Katılımcıların hepsi bir yıl düzenli yüzme antrenmanlarına katılmış gönüllü kişilerden seçilmiştir. Gönüllülerin, araştırmaya katımalarında sakınca görülecek herhangi bir sağlık problemleri olmamasına ve son bir yıl içerisinde ağır sportif yaralanma geçirmemiş olmalarına dikkat edilmiştir. Bahsedilen kriterleri karşılayan katıımcıların detaylı tanımlayıcı istatistikleri, Tablo 1'de sunulmaktadır. Katılımcılara ve ailelerine, araştırmanın amacı hakkında bilgi verilerek uygulanan testlere karşı istek ve tutumları artıııımaya çalışıımıştır. Ailelerden onam formları alınmıştır.

Çalışmanın sınırıııkları, 9-13 yaş grubu çocuklar, Düzce Gençlik Hizmetleri ve Spor Kulübü sporcuları, serbest yüzme tekniği, 50 metre bitimindeki derece, çift kol açık kulaç uzunluğu ve kulaç sayısı değişkenleri olarak belirlenmiştir. Araştırma betimsel model ile gerçekleştirilmiştir. 
Araştırma verileri, başlangıçta salon ölçümleri (antropometrik ve motorik özellikler) takip eden günde havuz ölçümleri (50 metre serbest teknik yüzme) olmak üzere iki farklı günde elde edildi. Salon ölçümleri Düzce Gençlik ve Spor il Müdürlüğü Spor Salonunda, havuz ölçümleri ise Düzce Gençlik Spor il Müdürlüğü Yarı Olimpik Kapalı Yüzme Havuzunda yapıldı. Ölçüm sırasında havuz ve ortam sıcaklığı standartlara uygundu (havuz: 26 derece, ortam: 28 derece). Havuzdaki performans ölçümleri öncesinde, sporculara ısınma için; 400 metre serbest teknik ile yüzme ve 4X25 metre sprint çalışmaları yaptırıldı.

Yüzme performans ölçümleri için, sporculardan, kendilerini havuz içerisinden duvarı iterek (suda kayma) teste başlamaları istendi. Salon ölçümlerine başlamadan önce sporculara yaklaşık 30 dakika ısınma yaptıııldı. Isınmada; yaklaşık 15 dakika yürüme ve koşu çalışmaları, 15 dakika kol ve bacaklar ağırlıklı esnetme çalışmaları, ayak vuruşu çalışmaları, dikey sıçrama gibi yüzmeye özgü ısınma hareketleri yaptırıldı. Ölçümler öncesinde testin güvenilirliğini bozmamak amacıyla teste katılacak sporculara, şiddetli antrenmanlar yaptırımamıştır. Ayrıca sporculara testlerden en az iki saat öncesinde yemek yemeleri konusunda bilgilendirme yapılmıştır. Ölçüm olarak, boy, kulaç, el uzunluğu ve vücut ağırlığı gibi antropometrik ölçümler, kavrama kuvveti, sürat, dayanıklılı, çeviklik, esneklik gibi motorik ölçümler ve 50 metre serbest teknik yüzme (Crawl) performans ölçümleri alındı.

\section{Veri Toplama Araçları}

Bu bölümde araştırma sürecinde kullanılan antropometrik, motorik ve yüzme performansına yönelik testlerle ilgili bilgiler sunulmuşstur.

\section{Antropometrik ölçümler}

Vücut Ağırlığı. Ölçüm sporcu tişört ve şortlu iken ve çıplak ayakla yapıldı. Sporcunun ölçüm sırasında hafif kıyafetler giymesine özen gösterildi. Ölçümde elektronik tartı kullanıldı (Günay vd., 2005).

Boy Uzunluğu. Boy uzunluğu sporcu düz bir zemin üzerindeyken ve çıplak ayakla ölçüldü. Sporcunun ölçüm sırasında ağırığını iki ayağına da eşit bir şekilde dağıtılmış olmasına, topuklarının birleşik ve kürek kemikleri duvara yaslanmış durumda olmasında dikkat edildi. Ölçümde mezura kullanıldı (Günay vd., 2005).

Kulaç Uzunluğu. Sırt duvara dayalı kollar yana açılmış ve avuçlar yere paralel bakacak şekilde sağ ve sol el parmak uçları arasındaki en uzun mesafe mezura kullanılarak ölçüldü (Günay vd., 2005).

El Uzunluğu. Ön kol horizontal düzlemde, kaliperin bir ucu Radius kemiğinin styloid çıkıntısında, diğer ucu orta parmağın uç noktasındayken ölçüm alındı (Günay vd., 2005).

\section{Motorik ölçümler}

Sürat Testi. Katıımcıların süratlerini belirlemek için 30 metre sprint koşu testi uygulandı. Newtest 300 (Finlandiya) test bataryasında yer alan fotoseller 0-30 metrelik mesafelere yerleştirildi. Oyuncular başlangıç çizgisinin gerisinden koşuya başladı, test öncesi hı almalarına izin verilmedi. Bitiş çizgisi bitiminde yer alan kapı geçildiğinde 30 metre koşu derecesi bilgisayara aktarılarak saniye cinsinden kaydedildi (Günay vd., 2005).

Esneklik Testi. Esnekliği ölçmek için otur-eriş testi yapıldı. Otur-eriş esneklik testi için, uzunluğu 35 $\mathrm{cm}$, genişliği $45 \mathrm{~cm}$ ve yüksekliği $32 \mathrm{~cm}$, üst yüzey uzunluğu $55 \mathrm{~cm}$, üst yüzey genişliği $45 \mathrm{~cm}$, ayrıca ayakların dayandığı yüzeyden $15 \mathrm{~cm}$ dışarıda olan üst yüzey üzerinde $0-50 \mathrm{~cm}$ 'lik ölçüm cetveli 
bulunan bir sehpa kullanıldı. Katılımcıdan yere oturarak bacaklarını birbirine paralel olacak şekilde, dizleri bükmeden ayak tabanları sehpanın ön yüzüne değecek şekilde durması istendi. Kollarını olabildiği kadar ileriye uzatarak sehpanın üst yüzeyinde yer alan metrik pano üzerinde parmak uçlarının değdiği son noktada, 2 saniye beklemesi istendi. Metrik panoda temas edilen son nokta belirlenerek kaydedildi. Bekleme öncesinde ya da bekleme anında katılımcının bacakları bükülüp yer ile teması kesildiğinde, ölçüm geçersiz sayıldı, test tekrar yaptırıldı (Günay vd., 2005).

Dayanıklılık, Aerobik Kapasite Testi. Maksimum oksijen tüketimi (MaxVO²) belirlemede saha testlerinden 20 m Mekik Koşusu (Shuttle Run) testi kullanıldı. Bu test; 8.5 km.s-1 (9 sn) ile başlayan ve her 1 dakikada koşu hızının 0,5 km.s-1 arttığı, 20 metrelik mesafenin gidiş-dönüş olarak koşulduğu, 23 seviyeden oluşan bir testtir. Her mekiğin sonunda $20 \mathrm{~m}$ çizgisinin üzerine veya ötesine bir ayağın konulması gerekmektedir. Sporcu 2 defa mekiği yakalamayı başaramazsa test sonlandırılmaktadır. Seviye ve mekik sayısı not edilmekte, test sonucu elde edilen mekik seviyeleri, MaxVO² derecesi olarak kayıt edilmektedir (Günay vd., 2005).

Kavrama Kuvveti Testi. Takkei marka el dinamometresi (Handgrip) ile ölçüm yapıldı. Katılımcı ayakta dururken ölçüm yapılan kol, vücuda $45^{\circ}$ 'lik açı ile bükülmeden ölçüm alınmıştır. Test, sağ ve sol el için ikişer defa tekrar edilmiş ve en yüksek değer, kayıt edilmiştir (Günay vd., 2005).

Çeviklik Testi. Çevikliğin ölçülmesi için T-testi kullanıldı. Uygulanan bu test sporcuların ileriye sprint, sağa-sola kayma ve geri-geri koşu gibi yön değiştirerek mesafe kat etme hızlarını tespit etmek için kullanımaktadır. Ölçüm elektronik fotosel (Newtest 300, Finlandiya) ile alındı. Sporcuya 2 deneme yaptırıldı ve test bitiminde elde edilen en iyi süre saniye (sn) cinsinden kaydedildi (Pauole vd., 2000).

\section{Yüzme performans ölçümleri}

Yüzme performans ölçümü için 50 metre mesafe tercih edildi. Sporculardan, kendilerini havuz içerisinden duvarı iterek (suda kayma) teste başlamaları istendi. Katılımcılar 'hazır' komutundan sonra düdük sesiyle birlikte teste başlandı. Farklı iki yüzme hakemi tarafından tutulan Casio marka kronometre ile yüzme süreleri tespit edildi. Sporculara 50 m yüzme testi, ikişer defa yapıldı. Testler arasında en az 4 dakika dinlenme süresi verildi. Tespit edilen en kısa yüzme süresi, en iyi derece olarak kaydedildi. Kulaç sayısı ölçümü, 50 m mesafe için her kulaç birer birer sayılacak şekilde, iki farklı yüzme hakemi tarafından görsel olarak sayıldı, adet olarak kaydedildi.

\section{Verilerin Analizi}

İstatistiksel analizler SPSS 22 paket programında, tanımlayıcı istatistik ve Pearson Korelasyon analizi yapıldı. Analizlerde anlamlıık düzeyi $(p<0.05)$ kabul edildi.

\section{Bulgular}

Kız ve erkek katılımcıların toplam tanımlayıcı istatistik değerleri Tablo 1'de görülmektedir. Tablo 2'de ise antropometrik özellikler ve 50 metre serbest teknik yüzme performansı arasındaki ilişkiler ortaya konmuştur. 50 metre yüzme derecesi ile boy $(r=,-574 ; p=, 025)$ ve kulaç uzunluğu $(r=,-666 ; p=, 007)$ değerleri arasında negatif yönde anlamlı ilişki olduğu tespit edilmiştir ( $p<.05$ ). Elde edilen bu anlamlı sonuçlardan, boy ve kulaç uzunluğu arttıkça, yüzme performansının olumlu etkilendiği anlaşılmaktadır. 
Tablo 1. Tanımlayıcı istatistikler

\begin{tabular}{lccccc}
\hline Değişkenler & $\boldsymbol{n}$ & Min & Maks & X & SS \\
\hline Yaş (yıl) & 15 & 9,00 & 13,00 & 11,53 & 1,24 \\
Boy Uzunluğu (cm) & 15 & 137,00 & 175,00 & 152,26 & 9,52 \\
Vücut Ağırlığı (kg) & 15 & 32,80 & 65,90 & 46,04 & 10,12 \\
BKı (\%) & 15 & 15,81 & 28,52 & 19,79 & 3,80 \\
Sürat (sn) & 15 & 4,32 & 6,36 & 5,49 &, 58 \\
Çeviklik (sn) & 15 & 15,28 & 20,21 & 17,19 & 1,51 \\
Esneklik (cm) & 15 & 9,50 & 37,00 & 25,06 & 7,56 \\
Dayanıklılık (kg.m/sn) & 15 & 20,00 & 74,00 & 38,20 & 15,79 \\
Kavrama Kuvveti Sağ (kg) & 15 & 15,30 & 36,00 & 21,08 & 5,11 \\
Kavrama Kuvveti Sol (kg) & 15 & 13,30 & 42,40 & 21,50 & 7,02 \\
El Uzunluğu sağ (cm) & 15 & 15,00 & 17,50 & 16,03 &, 83 \\
El Uzunluğu Sol (cm) & 15 & 14,50 & 17,50 & 16,16 &, 91 \\
Kulaç Uzunluğu (cm) & 15 & 138,00 & 179,00 & 152,80 & 11,14 \\
50 m Kulaç sayısı (adet) & 15 & 44,00 & 98,00 & 66,40 & 15,30 \\
50 m Yüzme Derecesi (sn) & 15 & 39,01 & 60,24 & 51,70 & 8,16 \\
\hline
\end{tabular}

Tablo 2. Antropometrik özellikler ile 50 metre serbest teknik yüzme performansı arasındaki ilişkiler

\begin{tabular}{lccc}
\hline Değişkenler & $\boldsymbol{n}$ & $\mathbf{r}$ & $\mathbf{p}$ \\
\hline Boy - 50 m yüzme derecesi & 15 & -.574 &, $025^{\star}$ \\
Ağırlık - 50 m yüzme derecesi & 15 &,- 036 &, 899 \\
BKi - 50 m yüzme derecesi & 15 & .323 &, 241 \\
El Uzunluğu (sağ) - 50 m yüzme derecesi & 15 &,- 414 &, 125 \\
El Uzunluğu (sol) - 50 m yüzme derecesi & 15 &,- 484 &, 068 \\
Kulaç Uzunluğu - 50 m yüzme derecesi & 15 &,- 666 &, $007^{\star *}$ \\
\hline
\end{tabular}

${ }^{*} p<.05,{ }^{* *} p<.01$

Kulaç sayısı değerleri ile 50 metre yüzme derecesi arasında pozitif yönde anlamlı ilişki olduğu tespit edilmiştir. ( $r=$,814; $p=, 000) \quad(p<.05)$. Elde edilen bu anlamlı sonuçtan, kulaç sayısının azalmasının, yüzme performansını olumlu etkilediği anlaşılmaktadır. Bu durum; Tablo 2'de de görüldüğü üzere kulaç uzunluğunun büyüklügünün, yüzme performansını olumlu etkilemesi nedeniyle, kulaç sayısının düşük olmasına sebep olduğu şeklinde açıklanabilir.

Tablo 3. Kulaç sayısı ile 50 metre serbest teknik yüzme performansı arasındaki ilişkiler

\begin{tabular}{lccc}
\hline Değişkenler & $\boldsymbol{n}$ & $\mathbf{r}$ & $\mathbf{p}$ \\
\hline Kulaç sayısı - 50 m yüzme derecesi & 15 &, 814 &, $000^{* *}$ \\
\hline
\end{tabular}

50 metre yüzme derecesi ile sürat değerleri arasında pozitif $(r=, 012 ; p=, 629)$, dayanıklılık değerleri $(r=$ -.567; $p=, 028)$ ve kavrama kuvveti (sol) değerleri $(r=-.546 ; p=, 035)$ arasında ise negatif yönde anlamlı ilişki olduğu tespit edilmiştir ( $p<.05$ ). Elde edilen bu anlamlı sonuçlardan; 30m sprint koşu testi derecesinin iyi olmasının, yüzme performansında da iyi derecelere neden olduğu anlaşılmaktadır. 
Ayrıca dayanıklıık ve kavrama kuvveti değerlerinin artmasının da yüzme performansını olumlu yönde etkilediği anlaşılmaktadır.

Tablo 4. Motorik özellikler ile 50 metre serbest teknik yüzme performansı arasındaki ilişkiler

\begin{tabular}{lccc}
\hline Değişkenler & $\boldsymbol{n}$ & $\mathbf{r}$ & $\mathbf{p}$ \\
\hline Sürat - 50 m yüzme derecesi & 15 &, 629 &, $012^{*}$ \\
Çeviklik - 50 m yüzme derecesi & 15 &, 421 &, 118 \\
Esneklik - 50 m yüzme derecesi & 15 &, 183 &, 513 \\
Dayanıklılık - 50 m yüzme derecesi & 15 & -.567 &, $028^{*}$ \\
$\begin{array}{l}\text { Kavrama Kuvveti (sağ) - 50 m yüzme } \\
\text { derecesi }\end{array}$ & 15 &,- 487 &, 066 \\
$\begin{array}{l}\text { Kavrama Kuvveti sol - 50 m yüzme } \\
\text { derecesi }\end{array}$ & 15 & -.546 &, $035^{*}$ \\
\hline
\end{tabular}

Sürat değerleri ile 50 metre serbest teknik yüzmedeki kulaç sayısı arasında pozitif yönde anlamlı bir ilişki olduğu tespit edilmiştir $(r=, 558 ; p=, 031)$ ( $p<.05)$. Elde edilen bu anlamlı sonuç; 30m sprint koşu testi derecesinin iyi olması ile kulaç sayısının az olması arasında doğru orantı bulunmaktadır şeklinde yorumlanabilir. Fakat kulaç sayısı, kulaç uzunluğu ile de bağlantılıdır. Tablo 2 ve z'de bu durum izah edilmiştir. Başka bir deyiş̧le; kulaç sayısı, kulaç uzunluğundan bağımsız düşünülmemelidir. Bu nedenle bahsedilen sonuçların, hepsinin birlikte değerlendirilmesi ile daha sağlıklı yorumlar yapılabilir.

Tablo 5. Motorik özellikler ile 50 metre yüzmedeki kulaç sayısı arasındaki ilişkiler

\begin{tabular}{|c|c|c|c|}
\hline Değişkenler & $\mathbf{n}$ & $r$ & $p$ \\
\hline Sürat - 50 m yüzmedeki kulaç sayısı & 15 & .558 & $.031^{*}$ \\
\hline Çeviklik - 50 m yüzmedeki kulaç sayısı & 15 & 497 &, 059 \\
\hline Esneklik - 50 m yüzmedeki kulaç sayısı & 15 & 210 & 453 \\
\hline Dayanıklılık - 50 m yüzmedeki kulaç sayısı & 15 &,- 342 & 213 \\
\hline $\begin{array}{l}\text { Kavrama Kuvveti (sağ) - } 50 \text { m yüzmedeki } \\
\text { kulaç sayısı }\end{array}$ & 15 &,- 180 & .520 \\
\hline $\begin{array}{l}\text { Kavrama Kuvveti (sol) - } 50 \text { m yüzmedeki } \\
\text { kulaç sayısı }\end{array}$ & 15 &,- 278 & 316 \\
\hline
\end{tabular}

\section{Tartışma}

Çalışmada, yaş ortalaması 11,53 $\pm 1,24$ yıl olan yüzücülerin; boy ortalaması 152,26 $\pm 9,52 \mathrm{~cm}$, vücut ağırlığı ortalaması 46,04 $\pm 10,12 \mathrm{~kg}$, beden kütle indeksi ortalaması (BKI) \% 19,79 $\pm 3,80$ el uzunluğu-sağ $16,03 \pm 0,83 \mathrm{~cm}$, el uzunluğu-sol 16,16 $\pm 0,91 \mathrm{~cm}$, kulaç uzunluğu 152,80 $\pm 11,14 \mathrm{~cm}$ ve kulaç sayısı 66,40 $\pm 15,30$ adet olarak tespit edildi (Tablo 1). Selçuk ve Karacan (2017) 11-13 yaş aralığındaki erkek yüzücüler üzerinde yaptıkları çalışmada, ortalama boy değerlerinin $147.75 \mathrm{~cm}$, vücut ağırlığı değerlerinin 41,91 kg olduğunu ifade etmişlerdir. Yüksek ve diğerleri (2017) 9-12 yaş grubu erkek ve kız yüzücüler ile yaptıkları çalışmada, ortalama değerleri boy için kızlarda 150,63 cm, vücut ağırlığı için 47,88 kg, kulaç uzunluğu için 145,5 cm, erkeklerde ise boy için $148 \mathrm{~cm}$, vücut ağırlığı için $41,5 \mathrm{~kg}$, kulaç uzunluğu için $144,1 \mathrm{~cm}$ olarak tespit etmişlerdir. Araştırmamı sonucunda elde edilen boy, vücut 
ağırlığı ve kulaç uzunluğu ortalama değerleri, önceki çalışmalar ile karşılaştırıldığında elde edilen sonuçların, çalışmamız lehine daha yüksek olduğu görülmektedir.

Yaş aralığı 11-12 yıl olan kız ve erkek yüzücüler ile yapılan çalışmada en iyi performans gösterenlerin, uzun boylu, büyük yüzey alanına ve en iyi kulaç mekaniğine sahip olanlar olduğu ifade edilmektedir (Morais vd., 2013). Çalışmamızda da boy uzunluğu ve $50 \mathrm{~m}$ yüzme performansı arasında anlamlı negatif ilişki tespit edilmiştir (Tablo 2). Elde edilen bu sonuç, artan boy uzunluğunun, yüzme derecesini olumlu yönde etkilediği ifadesini destekler niteliktedir.

Boy ile beden ağırlığı arasındaki oran; beden kütle indeksi (BKi), optimal (amaca uygun) değere ne kadar yakınsa o kadar ideal olmaktadır. Vücut ağırığı ve yüzme performansı arasındaki ilişki için kaynak araştırıldığında; vücut ağırlığı değerlerinin, yüzücülerin toplam yüzme sürelerini etkileyen faktörlerden biri olduğunun ifade edildiği görülmüştür (Kılıç vd., 2002). Başka bir çalışmada da $50 \mathrm{~m}$ serbest teknik yüzme performansının, vücut ağırlığı ile ilişkili olduğu ve vücut ağırlığı artışının performans üzerinde negatif etki oluşturduğu anlaşılmaktadır (Özlü ve Akkuş, 2016). Çalışmamız sonucunda ise vücut ağırlığı ve BKi değerleri ile 50 m yüzme performansı arasında anlamlı ilişki tespit edilmemiştir (Tablo 2). Bu durumun; yaş grupları ve katıımcı sayılarının, literatürdeki çalışmalar ile farklı olmasından kaynaklandığı düşünülmektedir.

Yüzme performansında etkili olduğu düşünülen diğer iki değişken olan kulaç uzunluğu ve kulaç sayısı ile ilgili yapılan literatür incelemesinde ise şu sonuçlara ulaşılmıştır; Ölmez ve diğerleri (2017) 8-12 yaş grubundaki yüzücüler ile yaptıkları çalışmada, kulaç uzunluğu ile 50 metre serbest teknik yüzme performansı arasındaki ilişkileri incelemişlerdir. Sonuç olarak, bahsedilen iki değişken arasında anlamlı negatif bir ilişki olduğunu ifade etmişlerdir. Başka bir çalışmada da 20 erkek yüzücünün, $50 \mathrm{~m}$ serbest teknik yüzme performansında etkili olan değişkenler incelenmiştir. Sonuç olarak, $50 \mathrm{~m}$ yüzme performansı ile kulaç, boy ve kol uzunluğu arasında anlamlı negatif ilişkiler bulunduğu ifade edilmiştir (Hlavaty, 2010). Çalışmamızda da 50 m yüzme performansı ile boy ve kulaç uzunluğu değerleri arasında anlamlı negatif ilişki olduğu tespit edilmiştir (Tablo 2). Bu sonuç, bahsedilen önceki araştırma sonuçları ile benzerdir. Bu sonuçlardan, boy ve kulaç uzunluğunun büyük olmasının, yüzme yarışlarında kısa mesafe olarak kabul edilen 50 m yüzme performansındaki dereceleri olumlu yönde etkilediği anlaşılmaktadır. Kulaç sayısı ile ilgili yapılan bir araştırmada da kulaç sıklığının, yüzme toplam süresi üzerinde etkili olduğu ifade edilmiştir (Kılıç vd., 2002). Çalışmamızda da kulaç sayısı ile 50 m yüzme performansı arasında anlamlı pozitif ilişki tespit edilmiştir (Tablo 3). Bu çıkan sonuç, önceki araştırma sonucuyla benzerlik göstermektedir.

Kulaç sayısı ve kulaç uzunluğu arasındaki ilişki incelendiğinde ise; yapılan bir çalışmada, 50 metre serbest yüzme tekniğinde 9-11 yaş grubu yüzücülerde, kulaç uzunluğu ve kulaç sayısının performansa etkisi araştırılmış ve sonuç olarak bu iki değişken arasında istatistiksel açıdan anlamlı bir ilişki olmadığı belirtmiştir (Kaya, 2012). Çalışmamızda da kulaç uzunluğu ile kulaç sayısı arasında, anlamlı bir ilişki olmadığı tespit edilmiştir ( $p$ >.05). Tüm bu araştırma sonuçlarından; kulaç uzunluğunun metrik olarak büyük olmasının, yüzme hızındaki dereceleri olumlu yönde etkilediği yüksek ihtimal ile söylenebilir. Kulaç sıklığı veya sayısının yüzme derecesine olan etkisinin ise sporcunun performansına ve/veya antropometrik yapısına bağlı olarak değişebildiği anlaşıımaktadır.

Yaş ortalaması 11,53 $\pm 1,24$ yıl olan çalışmamızdaki yüzücülerin motorik özellikleri ortalama değerleri; sürat (30m sprint) $5,49 \mathrm{sn}$, çeviklik (T testi) $17,19 \mathrm{sn}$, esneklik (otur-uzan testi) $25,06 \mathrm{~cm}$. ve dayanıklılı (mekik koşusu) 38,20 kg.m/sn olarak tespit edilmiştir. Süratin, birçok spor dalında performansı belirleyen bir parametre olduğu ifade edilmektedir. Sürat, antrenmanlarla geliştirilebilen bir motorik özelliktir. Literatürde, çocuklarda kısa mesafe sprint süresinin, olgunlaşmaya bağlı olarak erkek ve kız çocuklarda ergenliğe kadar yakın gelişme gösterdiği, sürekli arttığı ve neredeyse bu dönemde 
cinsiyetler arasında performansta farklıı̆ıı hiç ortaya çıkmadığı belirtilmektedir (Muratlı, 2007). Ergen sporcularda $50 \mathrm{~m}$ serbest teknik yüzme performansının; erkeklerde, uzun atlama, yağsız vücut kütlesi, el kavrama kuvveti, aerobik dayanıklıık, boy uzunluğu ve hız (30 m sprint) değerleri ile kadınlarda ise sadece uzun atlama ve hız değerleri ile yüksek düzeyde anlamlı ilişkili olduğu yapılan bir araştırmada belirtilmektedir (Pardos-Mainer vd., 2016). Başka bir çalışmada da hem kızlar, hem de erkeklerde, 50 metre yüzme hızı ile hız testi (30 m sprint) dereceleri arasında anlamlı ilişkiler olduğu ifade edilmektedir (Tüzen vd., 2005). Çalışmamızda da $30 \mathrm{~m}$ sprint koşu testi değerleri ile $50 \mathrm{~m}$ serbest teknik yüzme derecesi ve kulaç sayısı arasındaki anlamlı pozitif ilişkiler (Tablo 4 ve 5), önceki çalışmaları desteklemektedir, bu sonuçlar literatürdeki bulgularla benzerlik göstermektedir.

Bir diğer motorik özellik olan kuvvet ortalama değeri tespiti için çalışmamızda, kavrama kuvveti ölçülmüştür. Kavrama kuvveti (izometrik kol kuvveti), kas boyunda uzama veya kısalma olmaksızın, kasın izometrik olarak kasılarak kuvvet üretmesini ifade etmektedir. Serbest teknik yüzmede kulaç atarken elin suya giriş ve uzanma safhasında dirsek eklemi ekstansiyona doğru gelmektedir. Bu aşamada, izometrik kas kasılması ile kuvvet üretilir (Toussaint \& Beek, 1992). Kavrama kuvveti, yüzücüler için önemli bir motorik özelliktir ve düzenli antrenmanlar ile geliştirilebilir (Poyraz vd., 2015). Bu nedenle çalışmamızda, kuvvet ölçümlerinden; izometrik kol kuvveti ölçümü tercih edilmiştir. Yapılan ölçümler sonucunda ortalama kavrama kuvveti değerleri, sağ kol için 21,08 kg., sol kol için 21,50 kg olarak tespit edilmiştir. Seiler ve diğerleri (2007) 13 yaşındaki elit yüzücüler ile yaptıkları 6 aylık çalışma sonucunda, kavrama kuvveti değerlerinde, kara antrenmanı yapan grupta anlamlı, yapmayan grupta ise anlamlı ilişki bulunmadığını belirtmişlerdir. Başka bir çalışmada da en az 1 yıl spor geçmişi olan ve düzenli olarak haftada en az 2 gün antrenman yapan sporcuların kavrama kuvvetlerinin, spor yapmayan gruba göre daha yüksek olduğu ifade edilmektedir (Bilim vd., 2016). Literatürde yer alan birçok araştırmada da, spor çalışmalarına katılan çocuklarda, kavrama kuvveti değerlerinde artış meydana geldiği belirtilmiştir (Backous vd., 1990; Katie vd., 2019; Yazarer vd., 2004). Zampagni ve diğerleri (2008) 50-800 metre serbest teknik yüzme performansına etki eden antropometrik ve motorik özellikleri incelediği çalışmasında, boy uzunluğu ve kavrama kuvveti değerlerinin; 50 metrede \%84, 100 metrede \%73, 200 metre ve 400 metrede \%66 ve 800 metrede \%63 oranında etkili olduğunu ifade etmişlerdir. Çalışmamızda da sol el-kavrama kuvveti ortalama değeri ile 50 m serbest teknik yüzme derecesi arasında anlamlı negatif ilişki olduğu tespit edilmiştir (Tablo 4). Bu sonuç, önceki çalışmalar ile benzerlik göstermektedir. Araştırma sonuçlarına göre kavrama kuvveti değerlerindeki artışın, yüzme hızını olumlu yönde etkilediği söylenebilir.

Kuvvet özelliğinin yanı sıra, esneklik çalışmaları, kuvvet gelişimine yardımcı olacağı için yüzme antrenman programlarına mutlaka eklenmelidir. Çünkü esneklik, kuvvetten ve hızdan en yüksek derecede yararlanılmasını sağlamada büyük bir yardımcı olarak görülmektedir. Ayrıca esnek kaslar, ani kuvvet uygulamalarında daha az sakatlanmaktadırlar (Maglischo, 2003). Esneklik çalışmaları, eklem hareketlerinin açısal derecelerini arttırarak, bütün vücudun suda rahat, düzgün kaymasını sağlamakta ve bu sayede sürtünme kuvvetini en az seviyeye düşürmektedir. Bu durum, yüzme esnasında sürtünme kuvvetini azaltmaya çalışan yüzücüler için çok önemlidir. Esneklik; yüzücünün, verimli, yumuşak, gösterişli ve daha hızlı yüzmesini sağlamaktadır. Hazırlanan esneklik programının yetersiz oluşu, sporcunun en üst performansa ulaşmasını olumsuz yönde etkilemektedir. Bu sebeple iyi yüzücülerin antrenörlerinin, antrenman programlarında esneklik çalışmalarına sıklıkla yer verdikleri belirtilmektedir (Hagerman, 2006). Diğer yandan, Jagomägi \& Jürimäe (2005) kurbağalama teknik ile yüzen elit yüzücülerle yaptıkları araştırmada, elit ve kontrol grubundaki esneklik değerlerini karşılaştırmış ve istatistiksel açıdan anlamlı bir fark olmadığını çalışma sonucunda belirtmişlerdir. Çalışmamızdaki yüzücülerin ortalama esneklik (otur-uzan testi) değeri $25,6 \mathrm{~cm}$ olarak tespit edilmiştir. Esneklik değerleri ile $50 \mathrm{~m}$ serbest teknik yüzme derecesi arasında istatistiksel olarak anlamlı ilişki bulunmamıştır (Tablo 4). Bu sonuç, bahsedilen önceki araştırma sonucuyla benzerlik göstermektedir. 
Fakat esnekliğin, yüzmede ne kadar önemli olduğu da anlaşılmaktadır. Bu konu hakkında yapılacak yeni çalışmalar ile daha da açıklayıcı yorumlar yapılabileceği düşünülmektedir.

Yüzmede kuvvet, sürat ve esneklik özelliğinin yanı sıra dayanıklılık da çok önemli bir motorik özelliktir (Bozdoğan, 2003; Çelebi, 2008; Özüak, 2009). Ergenlik döneminde çocuğun organizması hızı bir gelişme içerisindedir. Bu yüzden dayanıklıık antrenmanları için en uygun dönem ergenlik dönemidir. Zamana bağlı gelişim süreci ile dayanıklıık antrenmanı uyumlu olmaz ise performans geliştirilmemektedir (Muratlı, 2007). Çalışmamızda yüzme derecesini tespit için tercih edilen 50 metre, her ne kadar yüzmede kısa mesafe yarışlarından olsa da özellikle kısa süreli dayanıklıığın çok önemli ve gerekli olduğu bir mesafedir. Optimal beden ağırlığı, dayanıklıık verimliliği için belirleyici bir faktördür. Dayanıklıık seviyesi yüksek olan yüzücülerin, yüzme derecelerinin daha iyi olduğu ifade edilmektedir (Bozdoğan, 2003; Maglischo, 2003; Özüak, 2009). Çalışmamızda dayanıklıık seviyesini belirlemek için yapılan mekik koşusu testi ortalama değeri 38,20 kg.m/sn olarak tespit edilmiştir. Ayrıca dayanıklılık değeri ile 50 m serbest teknik yüzme derecesi arasında negatif anlamlı ilişki tespit edilmiştir (Tablo 4). Bu tespit, literatür bilgisini desteklemektedir. Bu sonuç ile çalışmamızdaki yüzücülerin dayanıklıık seviyelerinin iyi olduğu ve bu durumun, yüzme derecelerini olumlu yönde etkilediği söylenebilir.

Araştırmada ölçülen bir diğer motorik özellik olan çeviklik performansında ise 12-13 yaşları arasında en yüksek gelişimin görüldüğü ve ardından yavaşlayarak 15-16 yaşlarına kadar daha düşük gelişimin görüldüğü literatürde belirtilmektedir. Çeviklik insanın ve sporcunun genel olarak en karmaşık motorsal özelliğidir. Çeviklik özelliğinin içerisinde pek çok unsur yer alır; reaksiyon, hız, çabuk kuvvet, koordinasyon, denge vb. gibi (Muratlı, 2007; Vescovi vd., 2011). Çalışmamızdaki ortalama çeviklik değeri 17,12 sn olarak tespit edilmiştir, çeviklik değerleri ile $50 \mathrm{~m}$ serbest teknik yüzme derecesi ve kulaç sayısı değerleri arasında anlamlı ilişki bulunmamıştır (Tablo 4 ve 5). Araştırmadan elde edilen bu sonuçları tartışacak literatür bilgisine ulaşılamamıştır. Konuyla ilgili yapılacak ileride ki çalışmaların alana katkı sunacağı düşünülmektedir. Araştırmadan elde edilen bu sonuçları tartışacak literatür bilgisine ulaşılamamıştır. Konuyla ilgili yapılacak ilerideki çalışmaların alana katkı sunacağı düşünülmektedir. Yapılacak yeni çalışmalar ile bu konu hakkında daha sağlıklı yorumlar yapılabileceği düşünülmektedir.

\section{Sonuç ve Öneriler}

Çalışma sonucunda, kısa mesafedeki yüzme derecelerini, antropometrik özelliklerden; beden kütle indeksi, boy ve kulaç uzunluğu, motorik özelliklerden; sürat, dayanıklılık, kavrama kuvveti ve ayrıca kulaç sayısının olumlu yönde etkilediği tespit edilmiştir. Yüzme antrenörlerine ve beden eğitimi öğretmenlerine, yetenek seçimi yaparken bahsedilen özelliklere dikkat etmeleri ve bunları geliştirecek yönde planlamalar yaparak antrenman yaptırmaları önerilmektedir.

\section{Kaynakça}

Backous, D.D., Farrow, J.A. \& Friedl, K.E. (1990). Assessment of pubertal maturity in boys using height and grip strength. Journal of Adolescent Health Care, 11 (6): 497-500.

Bilim, A.S., Çetinkaya, C. \& Dayı, A. (2016). 12-17 Yaş arası spor yapan ve spor yapmayan öğrencilerin fiziksel uygunluklarının incelenmesi. Spor ve Performans Araştırmaları Dergisi, 7(2), 53-60.

Bozdoğan, A. \& Özüak, A. (2003). Tüm stilleriyle temel yüzme. İstanbul: Illpress Basım ve Yayın.

Çelebi, Ş. (2008). Yüzme antrenmanı yaptırılan 9-13 yaş gurubu ilköğretim öğrencilerinde vücut yapısal ve fonksiyonel özelliklerinin incelenmesi. Yayımlanmamış Yüksek Lisans Tezi. Erciyes Üniversitesi, Sağlık Bilimleri Enstitüsü, Kayseri. 
Gómez-Bruton, A., Matute-Llorente, A., Pardos-Mainer, E., González-Agüero, A., Gomez-Cabello, A., Casajús, J.A. \& Vicente-Rodriguez, G. (2016). Factors affecting children and adolescents 50 meter performance in freestyle swimming. Journal of Sports Medicine Physical Fitness, 56(12), 1439-1447.

Güler, ç.G. (2000). 9-18 Yaş grubu müsabık yüzücülerde eklem hareket genişliğinin ve antropometrik parametrelerin yüzme performansı ile ilişkisi ve bunu temel alan yeni bir esneklik programının düzenlenmesi. Yayımlanmamış Doktora Tezi. Marmara Üniversitesi Sağlık Bilimleri Enstitüsü, istanbul.

Günay, M., Tamer, K. \& Cicioğlu, i. (2005). Spor fizyolojisi ve performans ölçümü. Gazi Kitapevi, Ankara. Hagerman, P.S. (2006). Flexibility for swimming. NSCA's Performance Training Journal, 17),

Helmuth, H.S. (1980). Anthropometric survey of young swimmers. Anthropologischer Anzegie, 38 , 17-34.

Hlavatý, R. (2010). The anthropometric and kinematic determinants of swimming performance. Joint International IGIP-SEFI Annual Conference, 19th - 22nd September, Trnava, Slovakia.

Jagomägi, G. \& Jürimäe, T. (2005). The influence of anthropometrical and flexibility parameters on the results of breaststroke swimming. Anthropologischer Anzegier, 63(2), 213-219.

Jürimae, J., Haljaskte, K., Cicchella, A., Latt, E., Purge, P., Leppik, A. \& Jürimae, T. (2007). Analysis of swimming performance from physical, physiological and biomechanical parameters in young swimmers. Pediatry Exercise Science, 19, 70-81.

Katie, M.M., Brad, S.M., Joanne, K., Linda, D.V. \& Terence, J.W. (2003). Contribution of timetabled physical education to total physical activity in primary school children: Cross sectional study. BMJ, 327(7415): 592-593.

Kaya, B. (2012). 9-11 Yaş grubu yüzücülerde kulaç uzunluğu ve sıklığının performansa etkisi. E- Journal of New World Sciences Academy. 7(2), 27-36.

Kılıç, T, Meriç, B. \& Aydın, M. (2002). 50 m. ve 100 m. serbest stil yüzmede kulaç uzunluğu ve kulaç sıklığının hıza etkisi, VII Uluslararası Spor Bilimleri Kongresi, 27-29 Ekim, Antalya, Türkiye.

Latt, E., Jürimae, J., Maestu, J., Purge, P., Ramson, R., Haljaste, K., Keskinen, K.L., Rodriquez, F.A. \& Jürimae, T. (2010). Physiological, biomechanical and anthropometrical predictors of sprint swimming performance in adolescent swimmers. Journal of Sports Science Medicine, 9: 398-404.

Maglischo, E.W. (2003). Swimming fastest. Human Kinetics: Champaign, IL.

Morais, J.E., Garrido, N.D., Marques, M.C., Silva, A.J., Marinho, D.A. \& Barbosa, T.M. (2013). The influence of anthropometric, kinematic and energetic variables and gender on swimming performance in youth athletes. Journal of Human Kinetics, 39: 203-211.

Muratı, S. (2007). Antrenman Bilimi Yaklaşımıla Çocuk ve Spor. Ankara: Nobel Yayıncılık.

Ölmez, C., Yüksek, S., Üçüncü, M., Ayan, V. (2017). 8-12 yaş çocuklarda bazı motorik özellikler ile 50 metre serbest stil yüzme performansı arasındaki ilişkinin incelenmesi. Türkiye Klinikleri Journal of Sports Science, 9(3), 95-100.

Özlü, M. \& Akkuş, H. (2016). Effects of the anthropometric and kinematic parameters on $50 \mathrm{~m}$ freestyle swimming performances. Turkish Journal of Sport and Exercise, 18(1), 144-118.

Özüak, A. (2009). Orta mesafe yüzücülerin farklı kulaç sıklığı antrenmanlarının performansa etkisi. Yayımlanmamış Doktora Tezi. Marmara Üniversitesi, Sağlık Bilimleri Enstitüsü, İstanbul.

Pauole, K., Madole, K., Garhammer, J., Lacourse, M. \& Rozenek R. (2000). Reliability and validity of the T-test as a measure of agility, leg power, and leg speed in college-aged men and women. Journal of Strength and Conditioning Research, 14(4): 443-450.

Poyraz A, Baş, O., Ocak Y., Yıldırım I.., \& Tortop Y. (2015). Avrupa badminton takım şampiyonasına katılan sporcuların bazı fiziksel ve fizyolojik özelliklerinin karşılaştııılması. Spor ve Performans Araştırmaları Dergisi, 6(2): 121-133. 
Seiler, S, De Koning J.J. \& Foster, C. (2007). The fall and rise of the gender difference in elite swimmers anaerobic performance. Medicine Science Sports Exercise, 39(3): 534-40.

Selçuk, H. \& Karacan, S. (2017). 11-13 yaş grubu erkek yüzme sporcularında 12 haftalık terabant antrenmanının yüzme performansına etkileri. International Journal of Human Sciences, 14(4): 4658-4668.

Smith, D.J, Norris, S.R. \& Hogg, J.M. (2002). Performance evaluation of swimmers. Sports Medicine, 32(9): 539-554.

Tella, V., Llana, S., Madera, J. \& Navarro F. (2002). Evaluation of anthropometrical and kinematic parameters in young swimmers: a longitudinal study. Caceres: XXth International Symposium on Biomechanics in Sports, 64-67.

Toussaint, H.M. \& Beek, P.J. (1992). Biomechanics of competitive front crawl swimming. Sports Medicine, 13(1): 8-24.

Tüzen, B., Müniroğlu, S. \& Tanılkan, K. (2005). Kısa mesafe yüzücülerinin 30 metre sürat koşusu dereceleri ile 50 metre serbest stil yüzme derecelerinin karşılaştırılması. Spormetre Beden Eğitimi ve Spor Bilimleri Dergisi, 3(3), 97-99.

Vescovi, J.D., Rupf, R., Brown, T.D. \& Marques, M.C. (2011). Physical performance characteristics of high-level female soccer players 12-21 years of age. Scandinavian Journal of Medicine \& Science in Sports, 21(5), 670-678.

Vitor, F.M., \& Böhme, M.T. (2010). Performance of young male swimmers in the 100 meters front crawl. Pediatry Exercise Science, 22: 278-287.

Wakayoshi, K., D'Acquisto, L..J., Cappaert, J.M. \& Troup, J.P. (1995). Relationship between oxygen uptake, stroke rate, and swimming velocity in competitive swimming. International Journal of Sports Medicine, 16(1): 19-23.

Wakayoshi, K., Yoshida, T., Ikuta, Y., Mutoh, Y. \& Miyashita, M. (1993). Adaptations to six months of aerobic swim training. International Journal of Sports Medicine, 14(07), 368-372.

Yazarer, i, Taşmektepligil, M.Y., Ağaoğlu, S.Y., Ağaoğlu, S.A., Albay, F. \& Eker, H. (2004). Yaz spor okullarında basketbol çalışmalarına katılan grupların iki aylık gelişmelerinin fiziksel yönden değerlendirilmesi. Spormetre Beden Eğitimi ve Spor Bilimleri Dergisi. 2(4), 163-170.

Yüksek, S., Hatipoğlu, Ö., Ayan, V. \& Ölmez, C. (2017). 9-12 yaş yüzücülerde 50 metre sürat koşusu ile 25 metre serbest stil yüzme performansları arasındaki ilişkinin incelenmesi. Türkiye Klinikleri Journal of Sports Science 9(2), 57-64.

Zampagni, M.L., Casino, D., Benelli, P., Visani, A., Marcacci M. \& De Vito, G. (2008). Anthropometric and strength variables to predict freestyle performance times in elite master swimmers. The Journal of Strength \& Conditioning Research, 22(4), 1298-1307.

All rights reserved by Turkish Association of Physical Education Teachers. Tüm hakları Türkiye Beden Eğitimi Öğretmenleri Derneği'ne aittir. 